This item was submitted to Loughborough's Research Repository by the author.

Items in Figshare are protected by copyright, with all rights reserved, unless otherwise indicated.

\title{
Thermoregulatory responses during competitive wheelchair rugby match
} play

PLEASE CITE THE PUBLISHED VERSION

http://dx.doi.org/10.1055/s-0042-121263

PUBLISHER

Georg Thieme Verlag

VERSION

AM (Accepted Manuscript)

\section{PUBLISHER STATEMENT}

This work is made available according to the conditions of the Creative Commons Attribution-NonCommercialNoDerivatives 4.0 International (CC BY-NC-ND 4.0) licence. Full details of this licence are available at: https://creativecommons.org/licenses/by-nc-nd/4.0/

\section{LICENCE}

CC BY-NC-ND 4.0

\section{REPOSITORY RECORD}

Griggs, Katy, George Havenith, Michael J. Price, Barry Mason, and Vicky Goosey-Tolfrey. 2017. "Thermoregulatory Responses During Competitive Wheelchair Rugby Match Play". figshare. https://hdl.handle.net/2134/23134. 


\section{Thermoregulatory Responses during Competitive Wheelchair Rugby Match}

\section{Abstract}

4 The purpose of this study was to determine whether a player's physical impairment

5 or activity profile was related to the amount of thermal strain experienced during

6 wheelchair rugby match play. Seventeen elite wheelchair rugby players played a

7 competitive match, whilst activity profiles, measures of core and skin temperature,

8 heart rate and perceptual responses were taken. Players were divided into two groups

9 depending on their physical impairment; players with a cervical spinal cord injury, (n

$10=10)$ or non-spinal related physical impairment $(n=7)$. Total distance was lower

11 (4842 $\pm 324 \mathrm{~m}$ vs. $5541 \pm 316 \mathrm{~m}, \mathrm{p}<0.01$, ES = 2.2) and mean speed slower $(1.13 \pm$

$120.11 \mathrm{~m} \cdot \mathrm{s}^{-1}$ vs $1.27 \pm 0.11 \mathrm{~m} \cdot \mathrm{s}^{-1,} \mathrm{p}<0.03$, ES = 1.3) in players with a spinal cord

13 injury. Yet, the change in core temperature $\left(1.6 \pm 0.4^{\circ} \mathrm{C}\right.$ vs. $0.7 \pm 0.3^{\circ} \mathrm{C}, \mathrm{p}<0.01$, ES

$14=2.5$ ) was significantly greater in players with a spinal cord injury. In conclusion,

15 players with a spinal cord injury were under greater thermal strain during wheelchair

16 rugby match play, as a result of their reduced heat loss capacity, due to their physical

17 impairment and not because of their activity profile.

18 Keywords: Thermoregulation, Spinal cord injury, Tetraplegia, Paralympic sport 


\section{Introduction}

21 Wheelchair rugby (WCR) was originally developed for individuals with tetraplegia

22 (spinal cord injury (SCI) at the cervical region of the spinal cord). However, recent

23 changes to the International Wheelchair Rugby Federation (IWRF) classification

24 system have meant that individuals with other physical impairments, such as cerebral

25 palsy, multiple amputations and neuromuscular disease, are now eligible to compete.

26 Based on physical impairment, male and female WCR players whom compete

27 together are classified into 1 of 8 classification groups from 0.5 (most impaired) to

283.5 (least impaired, International Wheelchair Rugby Federation, International Rules

29 for the Sport of Wheelchair Rugby June (2013). In Internet:

30 http://www.iwrf.com/resources/iwrf_docs/Wheelchair_Rugby_International_Rules_

31 2015_English.pdf; (10 ${ }^{\text {th }}$ November 2015)). In individuals with a SCI, in addition to

32 the lack of voluntary control of their torso and upper limb dysfunction, they are also

33 thermoregulatory impaired [14] proportional to their lesion level [26]. Their

34 thermoregulatory impairment is due to a lack of central sudomotor and vasomotor

35 control below their lesion level [8, 17, 23]. For example, it has previously been

36 shown that athletes with tetraplegia exhibit greater thermal strain than athletes with

37 paraplegia (thoracic, lumbar, or sacral SCI) during intermittent wheelchair exercise

38 in $\sim 20^{\circ} \mathrm{C}$ [13]. Hence, players with tetraplegia within the same classification group

39 as players with a non-spinal related physical impairment (NON-SCI) may be at a

40 thermoregulatory disadvantage during WCR match play.

41 Studies have shown IWRF classification to be closely related to the volume of

42 activity elicited over a typical WCR quarter [31, 32, 34]. For example, high point

43 players (2.0-3.5 points) are capable of greater peak speeds and spend less time within 
44 low speed zones compared to low point players (0.5-1.5 points) [31]. Furthermore,

45 high point players are shown to have better ball-handling skills, such as interceptions

46 and passes made and caught [21, 22], most likely attributed to these players

47 occupying offensive rather than defensive roles [31]. Interestingly, despite the noted

48 thermoregulatory impairment of individuals with tetraplegia, no study to date has

49 examined the combination of thermal strain of WCR players during match play and

50 the associated activity profiles. Individual thermoregulatory outcomes during

51 exercise may be influenced by independent factors, such as the physical attributes of

52 body mass and body composition [16]. Although, it has also been suggested that a

53 smaller percentage of individual variability in thermoregulatory responses is

54 explained by body composition in the able-bodied [5], due to the atrophy of skeletal

55 muscle in the lower limbs, whether the same variability exists for individuals with a

56 SCI is currently unknown.

58 Whether a player's physical impairment, activity profile or physical attributes

59 predisposes them to a greater amount of thermal strain during match play has both a

60 practical and clinical importance. For instance, identifying players under greater

61 thermal strain could enable both the implementation of targeted cooling strategies

62 and a reduction in performance decrements due to a high core temperature.

63 Furthermore, by investigating players during actual match play a physical challenge

64 and psychological stress is attained that is difficult to replicate in a laboratory. Thus

65 the purpose of this study was twofold 1) to compare the thermoregulatory responses

66 and activity profiles of players with a SCI to those players with a NON-SCI during

67 competitive WCR and 2) in those players with a SCI determine whether their

68 classification, activity profile and/or physical attributes were related to the thermal 
69 strain experienced during competitive WCR. It was hypothesized that 1) players

70 with a SCI would be under a greater amount of thermal strain than players with a

71 NON-SCI during competitive WCR and 2) due to the greater activity levels of high

72 point players reported previously [31], high point players with a SCI would

73 experience a heightened thermal response.

75 Methods

76 Participants: Sixteen male and one female WCR player from the BT Great Britain

77 Wheelchair Rugby (GBWR) squad gave their written informed consent to participate

78 in this study in accordance with the Declaration of Helsinki and in line with the

79 ethical standards of the journal [15]. The study was approved by the University

80 Research Ethics Committee. Participants were divided into two groups, SCI (n = 10)

81 or NON-SCI $(\mathrm{n}=7$, Table 1$)$.

82 Experimental design: All participants completed an incremental exercise test to

83 exhaustion on a treadmill for determination of peak oxygen uptake $\left(\mathrm{VO}_{2 \text { peak }}\right)$. On

84 separate occasions participants played in a WCR game at the squad's usual training

85 venue and in SCI, seven participants had a dual-energy X-ray absorptiometry (DXA)

86 scan. Three SCI participants, had a history of high levels of ionising radiation in the

87 previous 12 months and were excluded from having a DXA scan.

88 Laboratory testing

89 Peak oxygen uptake $\left(\dot{V} O_{2 p e a k}\right)$. The incremental exercise test was completed on a

90 motorised treadmill (HP Cosmos, Traunstein, Germany) at a constant $1.0 \%$ gradient

91 as previously described [19]. In brief, the speed was continually increased by 0.2-0.4

$92 \mathrm{~m} \cdot \mathrm{s}^{-1}$ every $3 \mathrm{~min}$, dependent on the participant's level of impairment. A slower 
93 starting speed and smaller speed increments were adopted for SCI players with

94 higher lesion levels (e.g. C5/6) and lower point players (e.g. 1.5) for NON-SCI. The

95 test was terminated when participants were unable to maintain the speed of the

96 treadmill.

97 Body composition. Skinfold measurements (Harpenden Skinfold Callipers, Baty

98 International, West Sussex, UK) were taken for all participants $(n=17)$ in a seated

99 position from the biceps, triceps, subscapular and suprailliac to calculate the sum of

100 skinfolds (mm). However, to get a true reflection of body composition for

101 individuals with an SCI, according to recent studies, [12] a DXA scan was

102 performed for seven of SCI using a Lunar Prodigy Advance DXA scanner (GE

103 Lunar, Madison, WI, USA) following procedures procedures previously described

104 [18]. The compartments measured were total body fat and lean tissue mass. Total

105 body fat and lean tissue mass percentage was obtained from the total body fat mass

106 and lean tissue mass, respectively, divided by the total body mass. Body surface area

$107\left(\mathrm{~m}^{2}\right)$ was estimated by the Dubois formula [6].

108 Field testing

109 Match play. Participants were separated into teams in consultation with the GBWR

110 coach which consisted of four participants (classification points totalling 8.0), with

111 games refereed by an official following IWRF regulations (International Wheelchair

112 Rugby Federation, International Rules for the Sport of Wheelchair Rugby June

113 (2013). In Internet:

114 http://www.iwrf.com/resources/iwrf_docs/Wheelchair_Rugby_International_Rules_

115 2015_English.pdf; (10 ${ }^{\text {th }}$ November 2015)). 
116 The match was played on a standard indoor basketball court and consisted of four 8

117 minute quarters with the game clock stopped during any stoppages or when the ball

118 was out of play, in accordance with IWRF regulations (International Wheelchair

119 Rugby Federation, International Rules for the Sport of Wheelchair Rugby June

120 (2013). In Internet:

121 http://www.iwrf.com/resources/iwrf_docs/Wheelchair_Rugby_International_Rules_

122 2015_English.pdf; (10th November 2015)).

123 To obtain a continuous trace of $\mathrm{T}_{\text {core }}$ data, Cortemp data recorders (HQ Inc, Palmetto,

124 Florida) were attached in a secure position to the wheelchairs of up to three

125 participants per match, due to the availability of Cortemp data recorders. Due to a

126 disruption in connection between the pill and recorder the authors were not able to

127 obtain continuous data sets for all players, thus $\mathrm{T}_{\text {core }}$ values for the end of each

128 quarter were analysed. Therefore a total of seven matches were monitored. The

129 range of environmental conditions of the seven matches were $18.4-20.9^{\circ} \mathrm{C}$ and 31.1

$130-45.1 \%$ relative humidity. Participants were required to play the full duration of the

131 match and were not permitted to use any form of cooling strategy.

132 Activity profiles. A radio-frequency based indoor tracking system (ITS, Ubisense,

133 Cambridge, UK) was used to provide real-time analysis of WCR activity profiles [25,

134 31]. Briefly, each participant was equipped with a small, lightweight tag (25g) fitted

135 into the back of a global positioning system vest that communicated with six sensors 136 through ultra-wideband signals. Data collection commenced at the beginning and

137 terminated at the end of each quarter and was paused during periods of extended

138 stoppages (e.g. time-outs, equipment breaks), resulting in a mean collection time of $13917.5 \pm 1.5 \mathrm{~min} /$ quarter. 
140 Total distance travelled (m), distance travelled relative to time spent on court

$141\left(\mathrm{~m} \cdot \mathrm{min}^{-1}\right)$ and mean and peak speed were determined for each participant. Using the

142 mean peak speed $\left(\mathrm{V}_{\max }\right)$ from the match, five arbitrary speed zones were

143 individualised for each participant, as previously described [31]; very low ( $\leq 20 \%$

$144 \mathrm{~V}_{\max }$ ), low (21-50\% $\left.\mathrm{V}_{\max }\right)$, moderate (51-80\% $\left.\mathrm{V}_{\max }\right)$, high (81-95\% $\left.\mathrm{V}_{\max }\right)$ and very

145 high $\left(\geq 95 \% \mathrm{~V}_{\max }\right)$. The percentage of total match time spent in each speed zone was

146 determined for each individual. High intensity activities (HI, high and very high

147 speed zones) were extended to include the total number and distance covered during

148 these activities.

149 Thermoregulatory measures. Participants ingested a telemetry pill (HQ Inc, Palmetto,

150 Florida) for the measurement of core temperature $\left(\mathrm{T}_{\text {core }}\right) \sim 6-8 \mathrm{~h}$ prior to the start of

151 the match, to avoid the influence of ingested food or fluid on the temperature reading

152 in accordance with previous recommendations [4]. All matches were played at a

153 similar time in the afternoon to negate circadian variation [37]. Participants were

154 weighed before and after the match to the nearest $0.1 \mathrm{~kg}$ (Detecto, Cardinal Scale

155 Manufacturing Co., Webb City, Missouri, USA) and wore their usual competition

156 attire. Participants were allowed to drink ad libitum during breaks between quarters

157 and the volume of fluid was recorded. In addition to the absolute change in body

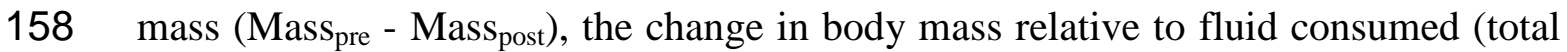

159 mass loss) was also calculated ((Mass pre $_{-}$Mass $\left._{\text {post }}\right)+$ fluid consumed).

160 Core temperature was measured by Cortemp data recorders at the end of each quarter,

161 by averaging three values taken over a 1 min period.. The rate of change in $\mathrm{T}_{\text {core }}$ was

162 calculated by the change in $\mathrm{T}_{\text {core }}$ over a quarter divided by the total time of the

163 quarter. Seven iButtons (DS1922T, Maxim Integrated Products, Inc., Sunnyvale, CA,

164 USA) were applied to the forehead and on the right side of the body at the forearm, 
165 upper arm (bicep), upper back, chest, thigh and calf prior to the 30 min warm-up led 166 by the coach.

167 In addition to individual skin temperatures, to compare to existing SCI literature, 168 mean skin temperature $\left(\mathrm{T}_{\mathrm{sk}}\right)$ was calculated in accordance with the formula by 169 Ramanathan [30]. Convective $\left(h_{c}\right)$ and evaporative $\left(h_{e}\right)$ heat transfer coefficients 170 were calculated using the following equations for a seated person [20]:

$$
\begin{aligned}
& h_{c}\left(W m^{-2} \cdot C^{-1}\right)=8.3(v)^{0.6} \\
& \mathrm{~h}_{e}\left(W m^{-2} \cdot C^{-1}\right)=16.5 h_{c}
\end{aligned}
$$

171 Where: $\mathrm{v}$ is the estimated player mean speed in $\mathrm{m} \cdot \mathrm{s}^{-1}$ from the ITS.

172 Heart rate and perceptual measures. Heart rate (HR) was continually recorded at $5 \mathrm{~s}$ 173 intervals (Polar PE 4000, Kempele Finland). Thermal sensation [35] was recorded at 174 the start of the match (categories ranged from 0.0 ["unbearably cold"] to 8.0

175 ["unbearably hot”] in 0.5 increments) and at the end of each quarter in addition to 176 ratings of perceived exertion (RPE, Borg scale) [3].

\section{Metabolic energy expenditure}

178 Metabolic energy expenditure (M) during the match was estimated using the minute-

179 average values for oxygen consumption $\left(\dot{\mathrm{V}}_{2}\right)$ in litres per minute and the respiratory 180 exchange ratio (RER) during the $\dot{\mathrm{VO}}_{2 \text { peak }}$ test. The metabolic cost of pushing at the 181 mean speed during each quarter was calculated from the plot of oxygen consumption 182 vs. mean speed using these data. Metabolic energy expenditure was calculated using 183 the equation below:

$$
M(\mathrm{~W})=V \dot{O}_{2} \frac{\left(\frac{R E R-0.7 \cdot \mathrm{e}_{c}}{0.3}\right)+\left(\frac{1-R E R \cdot e_{f}}{0.3}\right)}{60} \cdot 1000
$$


184 Where: $e_{c}$ is the caloric equivalent per litre of oxygen for the oxidation of 185 carbohydrates $(21.13 \mathrm{~kJ})$, and $\mathrm{e}_{\mathrm{f}}$ is the caloric equivalent per litre of oxygen for the 186 oxidation of fat $(19.62 \mathrm{~kJ})$.

\section{Statistical analysis}

188 Data analysis was performed using the Statistical Package for the Social Sciences

189 (SPSS version 22, Chicago, IL) and all data are presented as mean \pm SD. Normality 190 and homogeneity of variance were confirmed by Shapiro-Wilk and Levene's test, 191 respectively. One participant from the SCI group was stopped during the match due 192 to reaching the safety limit of a high $\mathrm{T}_{\text {core }}\left(39.5^{\circ} \mathrm{C}\right)$. Thus data analysis for SCI used 193 nine participants, except for the correlations between activity profiles, physical 194 attributes and end of match $\mathrm{T}_{\text {core }}$ where analysis was based on all ten participants. 195 Independent t-tests were used to analyse differences between SCI and NON-SCI in 196 participant characteristics, activity profiles, heat transfer coefficients and fluid 197 balance. Speed zones, heart rate, $\Delta \mathrm{T}_{\text {core, }} \Delta \mathrm{T}_{\mathrm{sk}}$, change in individual skin temperatures,

198 and perceptual responses were analysed using a mixed method analysis of variance

199 (ANOVA). For all comparisons where the assumption of sphericity was violated, a 200 Greenhouse-Geisser correction was applied. Where significance was obtained post201 hoc pairwise comparisons with a Bonferroni correction were conducted. Main effects 202 and interactions were accepted as statistically significant when $\mathrm{p} \leq 0.05$. Confidence 203 intervals (95\% CI) for differences are presented, alongside effect sizes (ES) to 204 supplement important findings. Effect sizes were calculated as the ratio of the mean 205 difference to the pooled standard deviation of the difference. The magnitude of the 206 ES was classed as trivial $(<0.2)$, small (0.2-0.6), moderate (0.6-1.2), large (1.2-2.0) 207 and very large $(\geqslant 2.0)$ based on previous guidelines [2]. Pearson's product-moment 
208 correlation test was used as appropriate. An a priori power analysis, conducted in

209 G*Power 3.1, revealed a sample size of 14 participants was required, with $90 \%$

210 power and an $\alpha$ of 5\%, based on findings from previous research [13].

\section{Results}

\section{Participant characteristics}

213 The two groups were similar in terms of body mass $(p=0.63)$ and sum of skinfolds

$214(p=0.39)$. Yet SCI were older $(p=0.04)$, demonstrated a lower $\dot{V} O_{2 p e a k}(p=0.01)$

215 and functional class than NON-SCI $(p=0.01$, Table 1$)$.

\section{Activity profiles}

218 Total $(\mathrm{p}<0.01, \mathrm{ES}=2.2,95 \% \mathrm{CI}=-1045.5$ to -352.5$)$ and relative distances $(\mathrm{p}=$

$2190.03, \mathrm{ES}=1.2,95 \% \mathrm{CI}=-15.5$ to 0.9$)$ travelled and mean speed $(\mathrm{p}=0.03, \mathrm{ES}=1.3$, $22095 \%$ CI $=-0.3$ to -0.1 ) revealed large ES and were significantly lower in SCI 221 compared to NON-SCI. Peak speed $(\mathrm{p}=0.10$, ES $=0.8,95 \% \mathrm{CI}=-0.8$ to 0.1 ), 222 number of $\mathrm{HI}$ activities ( $\mathrm{p}=0.57, \mathrm{ES}=0.4,95 \% \mathrm{CI}=-16.3$ to 8.3 ) and total distance 223 of the HI activities ( $\mathrm{p}=0.24$, $\mathrm{ES}=0.7,95 \% \mathrm{CI}=-136.9$ to 28.9 ) were not 224 statistically different between groups (Table 2).

Insert Table 2 here

226 The two groups did not differ in the percentage of total quarter time spent in each 227 speed zone $(\mathrm{p}>0.05)$. There was no difference across all 4 quarters in the 228 percentage of time spent in each speed zone, except SCI spent a significantly smaller 229 percentage of time in the high speed zone in the first quarter than NON-SCI $(0.8 \pm$ $230 \quad 0.4 \%$ vs. $1.8 \pm 0.7 \% ; \mathrm{p}<0.01)$ 
232 The absolute change in body mass was significantly greater in SCI than NON-SCI (p

$233=0.05$, ES $=1.1$, whilst there was no difference between groups for the amount of

234 fluid ingested $(\mathrm{p}=0.75$, ES $=0.1)$. Total mass loss was significantly lower in SCI

235 than NON-SCI $(\mathrm{p}=0.04$, ES $=1.1)$.

236 Prior to the warm-up $\left(37.0 \pm 0.4^{\circ} \mathrm{C}\right.$ vs. $\left.37.4 \pm 0.5^{\circ} \mathrm{C}, \mathrm{p}=0.01, \mathrm{ES}=0.90\right)$ and start of 237 the match $\left(37.6 \pm 0.4^{\circ} \mathrm{C}\right.$ vs. $38.1 \pm 0.3^{\circ} \mathrm{C}$ prior to start of the match; $\mathrm{p}<0.01$, ES = 238 1.4), absolute $\mathrm{T}_{\text {core }}$ was lower in SCI compared to NON-SCI. During the match the 239 change in $\mathrm{T}_{\text {core }}$ was greater $\left(1.6 \pm 0.4^{\circ} \mathrm{C}\right.$ vs. $0.7 \pm 0.3^{\circ} \mathrm{C}$ from the start to the end of 240 the match, $\mathrm{p}<0.01$, $\mathrm{ES}=2.5,95 \% \mathrm{CI}=0.5$ to 1.3 , Fig. 1 ). A large $\mathrm{ES}$ for final $\mathrm{T}_{\text {core }}$ 241 revealed warmer end $\mathrm{T}_{\text {core }}$ in SCI than in NON-SCI $\left(39.3 \pm 0.5^{\circ} \mathrm{C}\right.$ vs. $38.8 \pm 0.3^{\circ} \mathrm{C}$; $\mathrm{p}$ $242=0.06, \mathrm{ES}=1.7,95 \% \mathrm{CI}=0.1$ to 1.0 ). The rate of change in $\mathrm{T}_{\text {core }}$ was greater in SCI 243 than NON-SCI over each quarter $(\mathrm{p}<0.01)$.

245 Mean skin temperature was similar between groups at the start of the match (30.78 \pm $2460.80^{\circ} \mathrm{C}$ vs. $32.59 \pm 1.15^{\circ} \mathrm{C}$ for SCI and NON-SCI respectively, $\mathrm{p}=0.68, \mathrm{ES}=1.9$ ).

247 The change in $\mathrm{T}_{\text {sk }}$ was not different between groups or over time during the match 248 (Fig. 2, ES $=0.2, \mathrm{p}>0.05,95 \% \mathrm{CI}=-0.6$ to 0.9 ). In SCI, Fig. 2 shows $\mathrm{T}_{\mathrm{sk}}$ increased 249 at the end of quarter 2, whilst after an initial increase $\mathrm{T}_{\text {sk }}$ started to decrease at the 250 end of quarter 2 in NON-SCI. Changes in forearm, upper arm, chest, back, thigh and 251 calf skin temperatures during the match were similar between groups (all $\mathrm{p}>0.05$ ),

252 yet a main effect of time was only revealed for the forearm, upper arm and back (all $253 \mathrm{p}<0.05)$. The convective and evaporative heat transfer coefficients were 254 significantly lower for SCI than NON-SCI $(\mathrm{p}=0.03)$. 
256 Heart rate and perceptual measures

257 Heart rate was significantly lower in SCI than NON-SCI (100 \pm 20 bpm vs. $143 \pm 27$

258 bpm; $\mathrm{p}<0.01)$, yet there was no main effect of group or time for RPE $(\mathrm{p}>0.05)$ or

259 thermal sensation ( $p>0.05$ ). During the match, RPE increased from 13 to 16 and 12

260 to 16 whilst thermal sensation increased from 4 to 6 and 4 to 7 in SCI and NON-SCI,

261 respectively. Significant relationships were only apparent between the change in core

262 temperature with both thermal sensation $(r=0.37, p=0.02)$ and RPE $(r=0.82, p<$

263 0.01) for SCI. Thermal sensation was significantly negatively correlated with the

264 change in mean skin temperature for SCI $(r=-0.47, \mathrm{p}<0.01)$.

265 Metabolic energy expenditure

266 Differences between groups in metabolic energy expenditure did not reach

267 significance, but revealed a moderate ES (158 $\pm 44 \mathrm{~W}$ and $200 \pm 74 \mathrm{~W}$ for SCI and

268 NON-SCI, respectively, $\mathrm{p}=0.21$, $\mathrm{ES}=0.7,95 \% \mathrm{CI}=-105.5$ to 21.5 ).

269 Identifying WCR players under greatest thermal strain

270 For the seven SCI participants that underwent the DXA procedures, body mass was

$27165.8 \pm 4.2 \mathrm{~kg}$, body surface area was $1.85 \pm 0.11 \mathrm{~m}^{2}$, lean tissue mass was $46.2 \pm 6.6$

$272 \mathrm{~kg}$ and $70.2 \pm 9.0 \%$ and fat mass was $16.3 \pm 5.3 \mathrm{~kg}$ and $26.2 \pm 8.9 \%$. Relationships

273 between key variables are shown in Fig. 3. Thermal sensation and RPE were not

274 correlated with any of the activity profile measures, end $\mathrm{T}_{\text {core }}$ or physical attributes.

275

Insert Fig. $3 A+4 B$

276 Discussion 
277 This study, to our knowledge, is the first comparison of both the physiological 278 responses and activity profiles of players with a SCI and a NON-SCI during 279 competitive WCR. Using this novel approach, findings revealed that players with a 280 SCI experienced greater thermal strain than NON-SCI players despite covering 17\% 281 less distance and pushing on average $\sim 10 \%$ slower. Therefore, confirming our 282 primary hypothesis, players with a SCI were under a greater amount of thermal strain 283 compared to their NON-SCI teammates mainly due to the reduction in heat loss 284 capacity as a result of their impairment and not by the amount of work performed.

285 In line with previous data, players in the current study spent $\sim 80 \%$ of total quarter 286 time in the very low/low speed zones [31], with both groups spending a similar 287 percentage of total quarter time in each speed zone. Nevertheless, the lower mean 288 speed of SCI, and thus lower self-generated air flow, would have caused 289 significantly lower dissipation of heat by convection and evaporation, depicted by 290 the lower heat transfer coefficients. Furthermore, evaporative heat loss would be 291 minimal for SCI [9, 23], given the large body surface area of insensate skin. In 292 relation to heat generation, although metabolic energy expenditure was not 293 significantly different, the observed moderate effect size $(\mathrm{ES}=0.7)$ implies that 294 metabolic energy expenditure tended to be lower in SCI than NON-SCI during the 295 match. Thus, this suggests that heat production would also likely be lower. Field296 based testing has the benefit of testing players in their natural environment making 297 the results more relevant than laboratory testing. However, to ensure minimal 298 disturbance to the players, energy expenditure could not be measured during the 299 match and thus estimations of energy expenditure were taken from $\dot{\mathrm{V}} \mathrm{O}_{2 \text { peak }}$ 300 laboratory data. Nevertheless, combining the effects of both a loss of sweating 301 capacity and lower mean speed suggests players with a SCI are predisposed to a 
302 greater increase in $\mathrm{T}_{\text {core }}$ than NON-SCI, despite NON-SCI expending more energy

303 and potentially producing more heat during match play.

304 For NON-SCI, the production and evaporation of sweat triggered by the rising $\mathrm{T}_{\text {core }}$

305 would have caused a dissipation of heat lowering skin temperature, with the 306 increasing heat loss leading to the stabilisation of $\mathrm{T}_{\text {core }}$ by half-time [36]. Therefore,

307 effective heat loss occurred in NON-SCI, whilst the opposite was the case for SCI.

308 Due to the inactivation of the leg muscle pump, loss of sweating capacity and

309 vasomotor control below the lesion level [8, 17, 23], players with a SCI are unable to

310 dissipate the majority of heat produced through exercise leading to a continual

311 increase in $\mathrm{T}_{\text {core }}$ and $\mathrm{T}_{\mathrm{sk}}[13,27,29,36]$. Thus, convective heat loss through muscle

312 and skin blood flow, in addition to evaporative heat loss through sweating below the

313 lesion would be limited.

314 The warmer $\mathrm{T}_{\text {core }}$ at the end of the match $\left(39.3 \pm 0.5^{\circ} \mathrm{C}\right)$, coupled with the larger rate

315 of rise of $\mathrm{T}_{\text {core }}$ for SCI during WCR match play highlights the greater thermal strain.

316 Although it has been shown that able-bodied athletes can operate at greater core

317 temperatures during exercise without any sign of fatigue or heat illness [7], whether

318 a similar critical core temperature exists for players with tetraplegia is currently

319 unknown. For instance, anecdotally the player that was stopped at $39.5^{\circ} \mathrm{C}$ displayed

320 noticeable difficulties with decision-making during play. Of practical importance,

$321 \mathrm{~T}_{\text {core }}$ in athletes with tetraplegia continues to increase following exercise [13],

322 therefore a $\mathrm{T}_{\text {core }}$ of $39.3^{\circ} \mathrm{C}$ could be an additional concern if multiple matches are

323 played in succession, thus players will be starting the second match significantly

324 warmer than resting levels. 
325 Despite players with a SCI having a greater increase in $\mathrm{T}_{\text {core }}$ and $\mathrm{T}_{\mathrm{sk}}$ during match

326 play they did not perceive to be any warmer than NON-SCI. Significant relationships

327 between the change in $\mathrm{T}_{\text {core }}$ and thermal sensation and RPE were however apparent

328 for SCI. These relationships may be due to the concomitant and continuous increase

329 in $\mathrm{T}_{\text {core, }}$, thermal sensation and RPE during match play and may not represent a causal

330 relation. In able-bodied individuals, thermal sensation is largely dictated by skin

331 temperature, independent of $\mathrm{T}_{\text {core }}$ [33], yet a significant negative relationship was

332 apparent between the change in $\mathrm{T}_{\text {sk }}$ and thermal sensation for SCI. During exercise a

333 larger change in skin temperature may be needed to induce a change in thermal

334 sensation of similar magnitude $[10,24]$ or due to only a small portion of their body

335 (head, anterior of arms and shoulders) being sensate, the role of skin temperature for

336 thermal perceptions may be limited to a small surface area in SCI [1]. Whether

337 thermal sensation in SCI would have reflected dynamic changes in $\mathrm{T}_{\mathrm{sk}}$ is unknown.

338 A better understanding of thermal perceptions in SCI is greatly needed to assist

339 coaches and medical staff to gauge when and which players should be removed from

340 play due to thermal strain, as the results suggest that the players themselves cannot

341 judge their thermal strain reliably.

342 A limitation of the study may have been the inclusion of only one female WCR

343 player. Despite this being reflective of the GBWR squad at the time, her change in

$344 \mathrm{~T}_{\text {core }}$ and $\mathrm{T}_{\mathrm{sk}}$ was similar to a player of the same classification (0.5) being, on average,

$3450.4^{\circ} \mathrm{C}$ and $0.2^{\circ} \mathrm{C}$ different, for $\mathrm{T}_{\text {core }}$ and $\mathrm{T}_{\text {sk }}$, respectively, over the course of the match.

346 Thus, her inclusion in the study is justified, especially as large inter-individual

347 variation in thermoregulatory responses is common for individuals with a SCI [28, 348 29]. 
349 Preliminary data from the current study aimed to determine if certain physical 350 attributes or activity profiles were related to $\mathrm{T}_{\text {core }}$ at the end of the match in SCI.

351 Multifactorial inter-individual variability makes it challenging to determine factors

352 that predict heightened thermal strain [11]. However, the present study attempted to

353 enable the coach and support staff to identify WCR players at the greatest thermal

354 strain. From the correlation data for SCI, those with a greater $\dot{\mathrm{V}}_{2 \text { peak, }}$ larger body

355 mass, larger lean mass and body surface area, and/or were a higher point player,

356 showed a greater end $\mathrm{T}_{\text {core }}$. Of note in SCI, an individual with a larger body mass

357 likely indicates a larger amount of upper body mass due to muscular atrophy below

358 the lesion. In relation to functional ability, a greater end $\mathrm{T}_{\text {core }}$ was apparent for higher

359 point players covering a greater relative distance and mean speed, i.e. generating a

360 greater amount of metabolic heat. Therefore, within the SCI group, it is the players

361 with a greater amount of functional ability, typically linked to roles on court that

362 elicit greater distances and speeds that are under the greatest thermal strain. In fact

363 the player that was stopped due to a high $\mathrm{T}_{\text {core }}\left(>39.5^{\circ} \mathrm{C}\right)$ was a high point player and

364 had the greatest body mass and $\dot{\mathrm{VO}}_{2 \text { peak }}$ in the SCI group. Although the low number

365 of participants used to identify WCR players under the greatest thermal strain does

366 make drawing firm conclusions difficult, as a preliminary data set it does provide

367 greater detail and guidance for coaches and support staff on which players may need

368 greater attention in regards to cooling strategies or breaks in play.

369 Conclusion

370 The current study revealed that WCR players with a SCI are under a greater amount

371 of thermal strain compared to NON-SCI players during match play. Players with an

372 SCI covered less distance and had slower mean speeds, thus generating a smaller 
373 amount of heat than NON-SCI. Yet, these players were under greater thermal strain, 374 due to a reduction in heat loss capacity as a result of their SCI. Preliminary data 375 revealed players with a SCI with greater functional ability (high point players) tend

376 to produce more heat during play and be predisposed to a greater $\mathrm{T}_{\text {core }}$ response than

377 low point players. Practically, coaches and support staff should be aware of the

378 greater thermal strain experienced by these players and implement appropriate 379 cooling strategies and tactics.

380

381

382

383

384

385

386

387

388

389

390

391

392

393

394

395

396

397 
Table 1. Physical attributes and participant characteristics of the two groups of 399 wheelchair rugby players; spinal cord injured (SCI) and non-spinal related physical 400 impairment (NON-SCI).

\section{SCI}

NON-SCI

p value

\section{Including Cerebral}

Disability/ level of

$\mathrm{C} 5 / 6-\mathrm{C} 7$

SCI

(2 incomplete)

Palsy ( $\mathrm{n}=2)$, lower

limb deficiency

$$
(n=4) \text { and leg }
$$

amputation $(\mathrm{n}=1)$.
Age (years)
$30 \pm 5^{*}$
$23 \pm 5$
$p=0.04$

Body mass (kg)

$68.4 \pm 10.5$

$65.3 \pm 14.8$

$p=0.63$

Sum of four

skinfolds (mm)

$57.3 \pm 30.6$

$51.0 \pm 13.6$

$p=0.39$

$\dot{\mathrm{V}} \mathrm{O}_{\text {2peak }}\left(\mathrm{L} \cdot \mathrm{min}^{-1}\right)$

$1.4 \pm 0.3^{*}$

$2.4 \pm 0.7$

$p=0.01$

Training $\left(h \cdot\right.$ week $\left.^{-1}\right)$

$14 \pm 4$

$10 \pm 4$

$\mathrm{p}=0.09$

\section{Classification}

$0.5-2.5^{*}$

1.5-3.5

$\mathrm{p}=0.01$

*significantly different to NON-SCI, $\mathrm{p} \leq 0.05$.

402

403

404

405

406

407 
408 Table 2. Match play activity profiles during the wheelchair rugby match for spinal 409 cord injured (SCI) and non-spinal related physical impairment (NON-SCI).

\begin{tabular}{llll}
\hline & SCI & NON-SCI & p value \\
\hline Total distance $(\mathbf{m})$ & $4842 \pm 324^{*}$ & $5541 \pm 316$ & $\mathrm{p}<0.01$ \\
Relative distance $\left(\mathbf{m} \cdot \mathbf{m i n}^{-\mathbf{1}}\right)$ & $68.1 \pm 7.0^{*}$ & $76.3 \pm 6.4$ & $\mathrm{p}=0.03$ \\
Mean speed $\left(\mathbf{m} \cdot \mathbf{s}^{-\mathbf{1}}\right)$ & $1.13 \pm 0.11^{*}$ & $1.27 \pm 0.11$ & $\mathrm{p}=0.03$ \\
Peak speed $\left(\mathbf{m} \cdot \mathbf{s}^{-\mathbf{1}}\right)$ & $3.42 \pm 0.50$ & $3.76 \pm 0.18$ & $\mathrm{p}=0.10$ \\
Number of $\mathbf{H I}$ activities & $22 \pm 10$ & $26 \pm 13$ & $\mathrm{p}=0.57$ \\
Total distance of HI activities (m) & $134 \pm 45$ & $188 \pm 105$ & $\mathrm{p}=0.24$
\end{tabular}

$410 \mathrm{HI}=$ high intensity activities, combination of high (81-95\%Vmax) and very high

411 ( $\geq 95 \%$ Vmax $)$ speed zones.

$412 *$ significantly different to NON-SCI, $\mathrm{p} \leq 0.05$.

413

414

415

416

417

418

419

420

421 

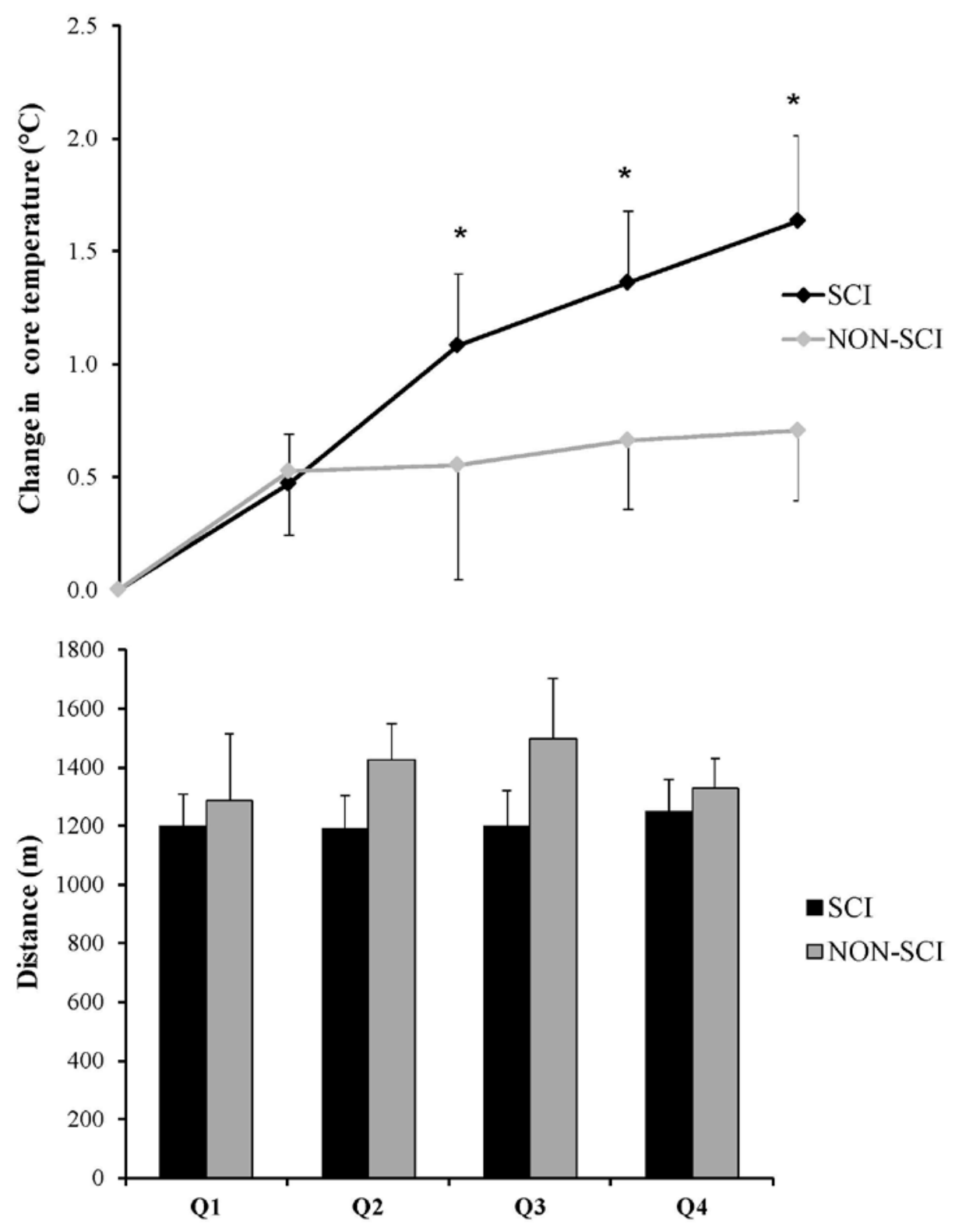

437 Fig.1 Distance travelled and change in core temperature over duration of the match 438 for spinal cord injured (SCI) and non-spinal related physical impairments (NON439 SCI). Q = quarter. * significantly different to NON-SCI, $\mathrm{p} \leq 0.05$. 


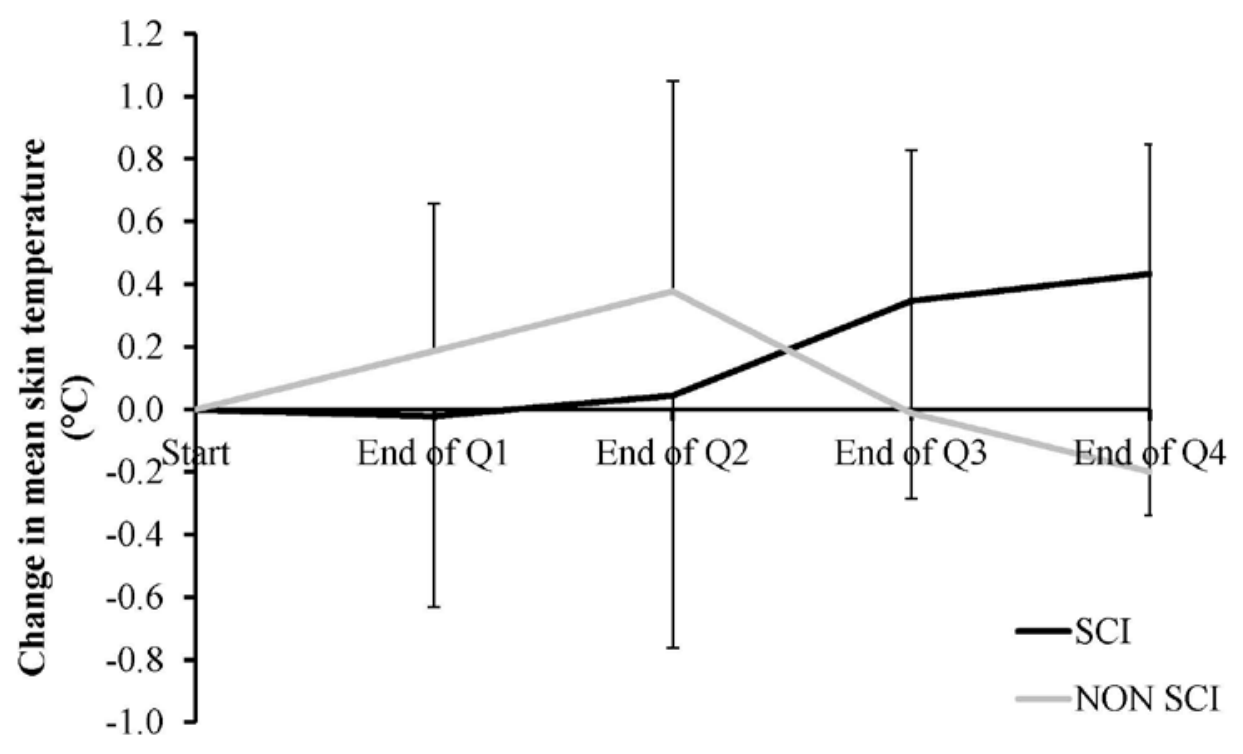

448

449

450 Fig.2 Change in mean skin temperature over the duration of the match for spinal 451 cord injured (SCI) and non-spinal related physical impairments (NON-SCI). Q = 452 quarter. *significantly different to NON-SCI, $\mathrm{p} \leq 0.05$. 

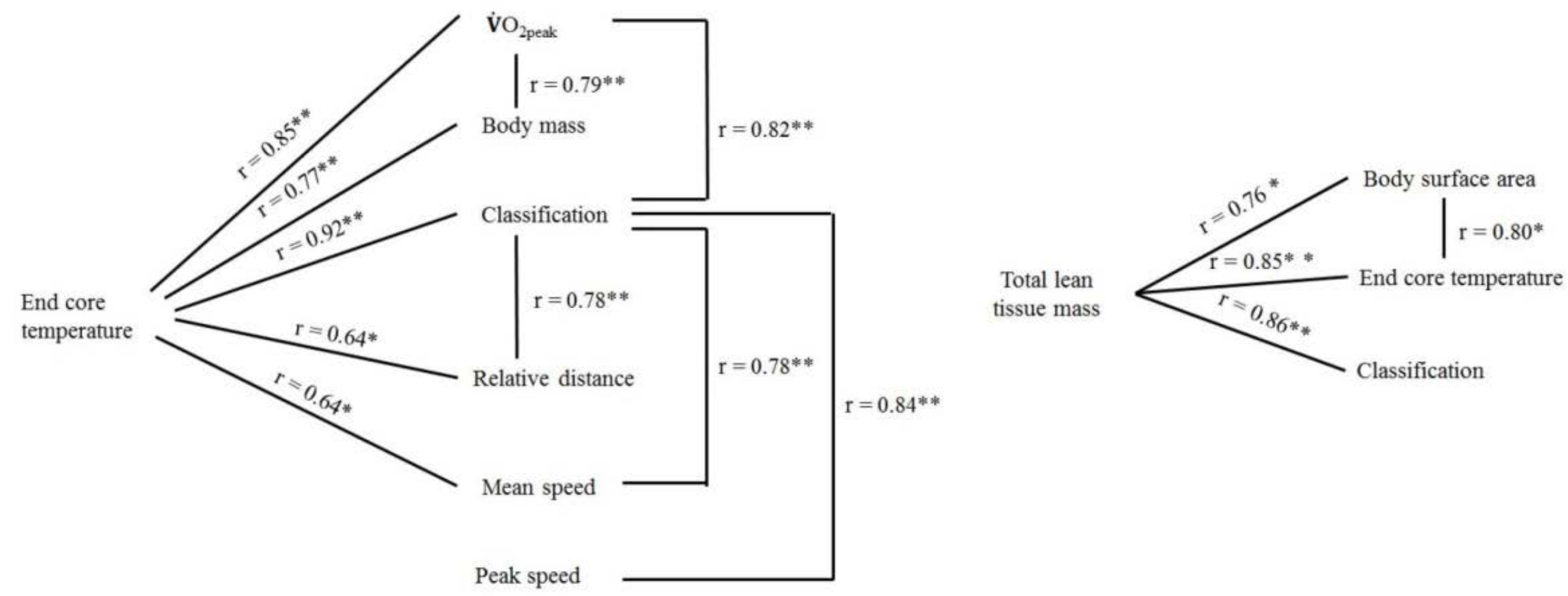

454 Fig.3 A) Relationship for spinal cord injured $(\mathrm{n}=10)$ between participant characteristics, physical attributes, activity profiles and thermal

measures. B) Relationship for spinal cord injured $(n=7)$ between dual-energy X-ray absorptiometry measures, participant characteristics and thermal measures. $\dot{V} O_{2 \text { peak }}=$ peak oxygen uptake, $*=$ significantly different at $\mathrm{p} \leq 0.05$, ** significantly different at $\mathrm{p} \leq 0.01$. 
458 1. Attia $M$, Engel $P$. Thermoregulatory set point in patients with spinal cord injuries 459 (spinal man). Paraplegia 1983; 21: 233-248.

460 2. Batterham AM, Hopkins WG. Making Meaningful Inferences About Magnitudes.

461 Int J Sports Physiol Perform 2006; 1: 50-57.

462 3. Borg G. Perceived exertion as an indicator of somatic stress. Scand J Rehabil Med 463 1970; 2: 92-98.

464 4. Byrne C, Lim CL. The ingestible telemetric body core temperature sensor: a 465 review of validity and exercise applications. Br J Sports Med 2007; 41: 126-133.

466 5. Cramer MN, Jay O. Explained variance in the thermoregulatory responses to 467 exercise: the independent roles of biophysical and fitness/fatness-related factors. J 468 Appl Physiol 2015; 119: 982-989.

469 6. Dubois, D and Dubois, E.F. A formula to estimate surface area if height and 470 weight are known. Arch Intern Med 1916; 17: 863.

471 7. Ely BR, Ely MR, Cheuvront SN, Kenefick RW, Degroot DW, Montain SJ. Evidence 472 against a 40 degrees $C$ core temperature threshold for fatigue in humans. J Appl 473 Physiol 2009; 107: 1519-1525.

474 8. Freund PR, Brengelmann GL, Rowell LB, Halar E. Attenuated skin blood flow 475 response to hyperthermia in paraplegic men. J Appl Physiol 1984; 56: 1104-1109.

476 9. Gass EM, Gass GC, Gwinn TH. Sweat rate and rectal and skin temperatures in 477 tetraplegic men during exercise. Sports Med Train Rehabil 1992; 3: 243-249.

478 10. Gerrett N, Ouzzahra Y, Coleby S, Hobbs S, Redortier B, Voelcker T, Havenith G. 479 Thermal sensitivity to warmth during rest and exercise: a sex comparison. Eur J Appl 480 Physiol 2014; 114: 1451-1462.

481 11. Girard O. Thermoregulation in wheelchair tennis-How to manage heat stress?. 482 Front Physiol 2015; 6: 175.

483 12. Goosey-Tolfrey V, Keil M, Brooke-Wavell K, de Groot S. A Comparison of 484 Methods for the Estimation of Body Composition in Highly Trained Wheelchair 485 Games Players. Int J Sports Med 2016; 37: 799-806.

486 13. Griggs KE, Leicht CA, Price MJ, Goosey-Tolfrey VL. Thermoregulation during 487 intermittent exercise in athletes with a spinal-cord injury. Int J Sports Physiol 488 Perform 2015; 10: 469-475.

489 14. Guttmann L, Silver J, Wyndham CH. Thermoregulation in spinal man. J Physiol 490 1958; 142: 406-419. 
491 15. Harriss DJ, Atkinson G. Ethical Standards in Sport and Exercise Science

492 Research: 2016 Update. Int J Sports Med 2015; 36: 1121-1124.

493 16. Havenith G, Fiala D. Thermal Indices and Thermophysiological Modeling for

494 Heat Stress. Compr Physiol 2015; in press.

495 17. Hopman MT. Circulatory responses during arm exercise in individuals with

496 paraplegia. Int J Sports Med 1994; 15: 126-131.

497 18. Keil M, Totosy dZ, Brooke-Wavell K, Goosey-Tolfrey V. Measurement precision

498 of body composition variables in elite wheelchair athletes, using dual-energy X-ray

499 absorptiometry. Eur J Sport Sci 2016; 16: 65-71.

500 19. Leicht CA, Griggs KE, Lavin J, Tolfrey K, Goosey-Tolfrey VL. Blood lactate and

501 ventilatory thresholds in wheelchair athletes with tetraplegia and paraplegia. Eur J

502 Appl Physiol 2014; 114: 1635-1643.

503 20. Mitchell D. Convective heat transfer from man and other animals. In: Monteith

504 JL, Mount LE (eds.). Heat Loss from Animals and Man: London, Butterworth, 1974:

505 59-76.

506 21. Molik B, Lubelska E, Koxmol A, Bogdan M, Yilla AB, Hyla E. An examination of

507 the international wheelchair rugby Federation classification system utilizing

508 parameters of offensive game efficiency. Adapt Phys Activ Q 2008; 25: 335-351.

509 22. Morgulec-Adamowicz N, Kosmol A, Bogdan M, Molik B, Rutkowska I,

510 Bednarczuk G. Game Efficiency of Wheelchair Rugby Athletes at the 2008

511 Paralympic Games with Regard to Player Classification. Human Movement 2010; 11:

512 29-36.

513 23. Normell LA. Distribution of impaired cutaneous vasomotor and sudomotor

514 function in paraplegic man. Scand J Clin Lab Invest Suppl 1974; 138: 25-41.

515 24. Ouzzahra Y, Havenith G, Redortier B. Regional distribution of thermal

516 sensitivity to cold at rest and during mild exercise in males. J Therm Biol 2012; 37:

$517 \quad 517-523$.

518 25. Perrat,B., Smith, M.J., Mason, B.S., Rhodes, J.M., Goosey-Tolfrey, V.L. Quality

519 assessment of an ultra-wide band positioning system for indoor wheelchair court

520 sports. J Sports Eng Technol 2015: 229: 81-91.

521 26. Price $M J$. Thermoregulation during exercise in individuals with spinal cord

522 injuries. Sports Med 2006; 36: 863-879.

523 27. Price MJ, Campbell IG. Effects of spinal cord lesion level upon

524 thermoregulation during exercise in the heat. Med Sci Sports Exerc 2003; 35: 1100-

5251107. 
526 28. Price MJ, Campbell IG. Thermoregulatory responses of paraplegic and able-

527 bodied athletes at rest and during prolonged upper body exercise and passive

528 recovery. Eur J Appl Physiol Occup Physiol 1997; 76: 552-560.

529 29. Price MJ, Campbell IG. Thermoregulatory responses of spinal cord injured and

530 able-bodied athletes to prolonged upper body exercise and recovery. Spinal Cord

531 1999; 37: 772-779.

532 30. Ramanathan NL. A New Weighting System for Mean Surface Temperature of

533 the Human Body. J Appl Physiol 1964; 19: 531-533.

534 31. Rhodes JM, Mason BS, Perrat B, Smith MJ, Malone LA, Goosey-Tolfrey VL.

535 Activity profiles of elite wheelchair rugby players during competition. Int J Sports

536 Physiol Perform 2015; 10: 318-324.

537 32. Sarro KJ, Misuta MS, Burkett B, Malone LA, Barros RML. Tracking of

538 wheelchair rugby players in the 2008 Demolition Derby final. J Sports Sci 2010; 28:

539 193-200.

540 33. Schlader ZJ, Simmons SE, Stannard SR, Muendel T. Skin temperature as a

541 thermal controller of exercise intensity. Eur J Appl Physiol 2011; 111: 1631-1639.

542 34. Sporner ML, Grindle GG, Kelleher A, Teodorski EE, Cooper R, Cooper RA.

543 Quantification of activity during wheelchair basketball and rugby at the National

544 Veterans Wheelchair Games: A pilot study. Prosthet Orthot Int 2009; 33: 210-217.

545 35. Toner MM, Drolet LL, Pandolf KB. Perceptual and physiological responses

546 during exercise in cool and cold water. Percept Mot Skills 1986; 62: 211-220.

547 36. Webb P. The physiology of heat regulation. Am J Physiol 1995; 268: R838-50.

548 37. Winget CM, DeRoshia CW, Holley DC. Circadian rhythms and athletic

549 performance. Med Sci Sports Exerc 1985; 17: 498-516.

550

551

552 